\title{
Implantação do Plano de Alta Multidisciplinar - PAMD em um Hospital Privado na cidade de Sáo Paulo
}

\section{Hospital Villa Lobos 2019}
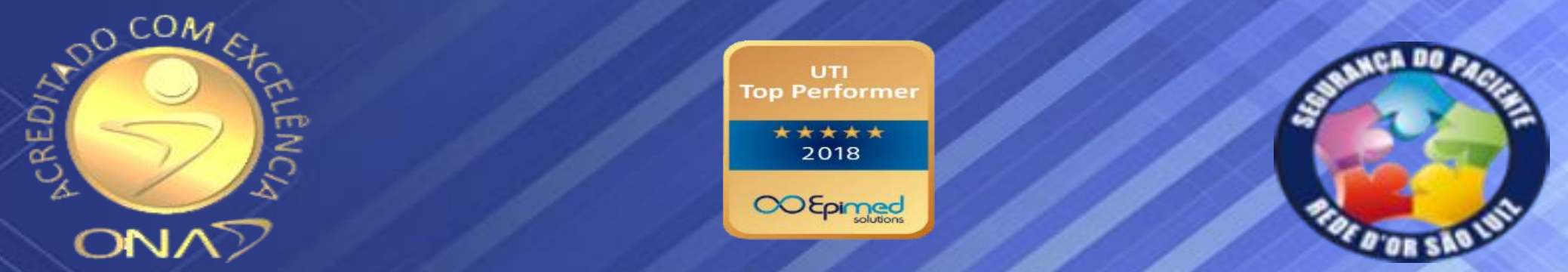

REDE $\mathscr{D O R}$

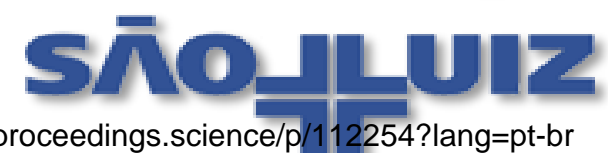




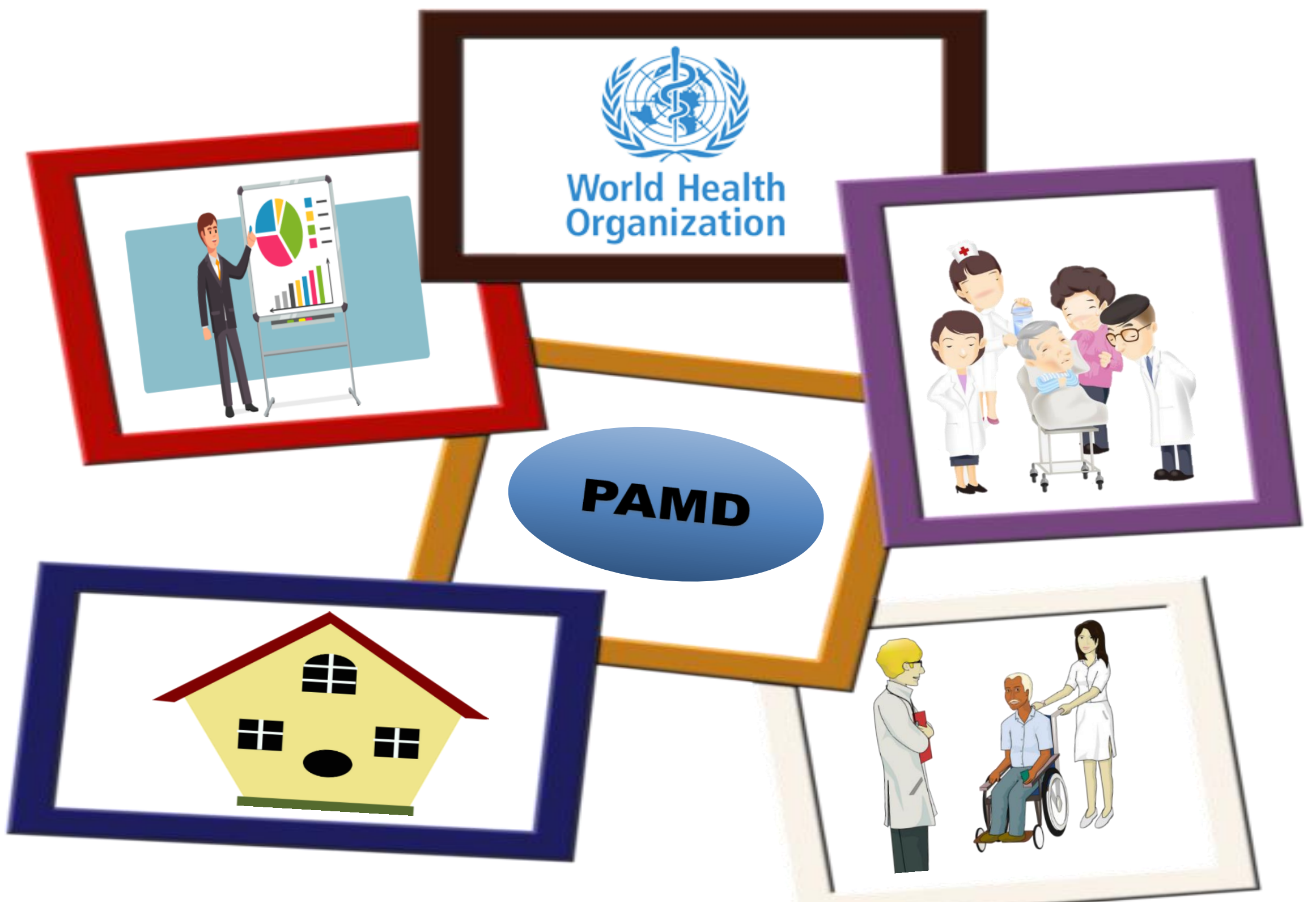


Otimizar o processo de alta.

Continuidade dos cuidados a serem realizados no pós alta.

Aumentar a satisfação e fidelização do cliente..

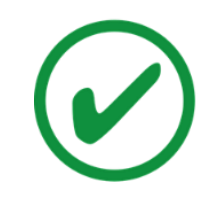

Potencializar melhoria no giro de leito.
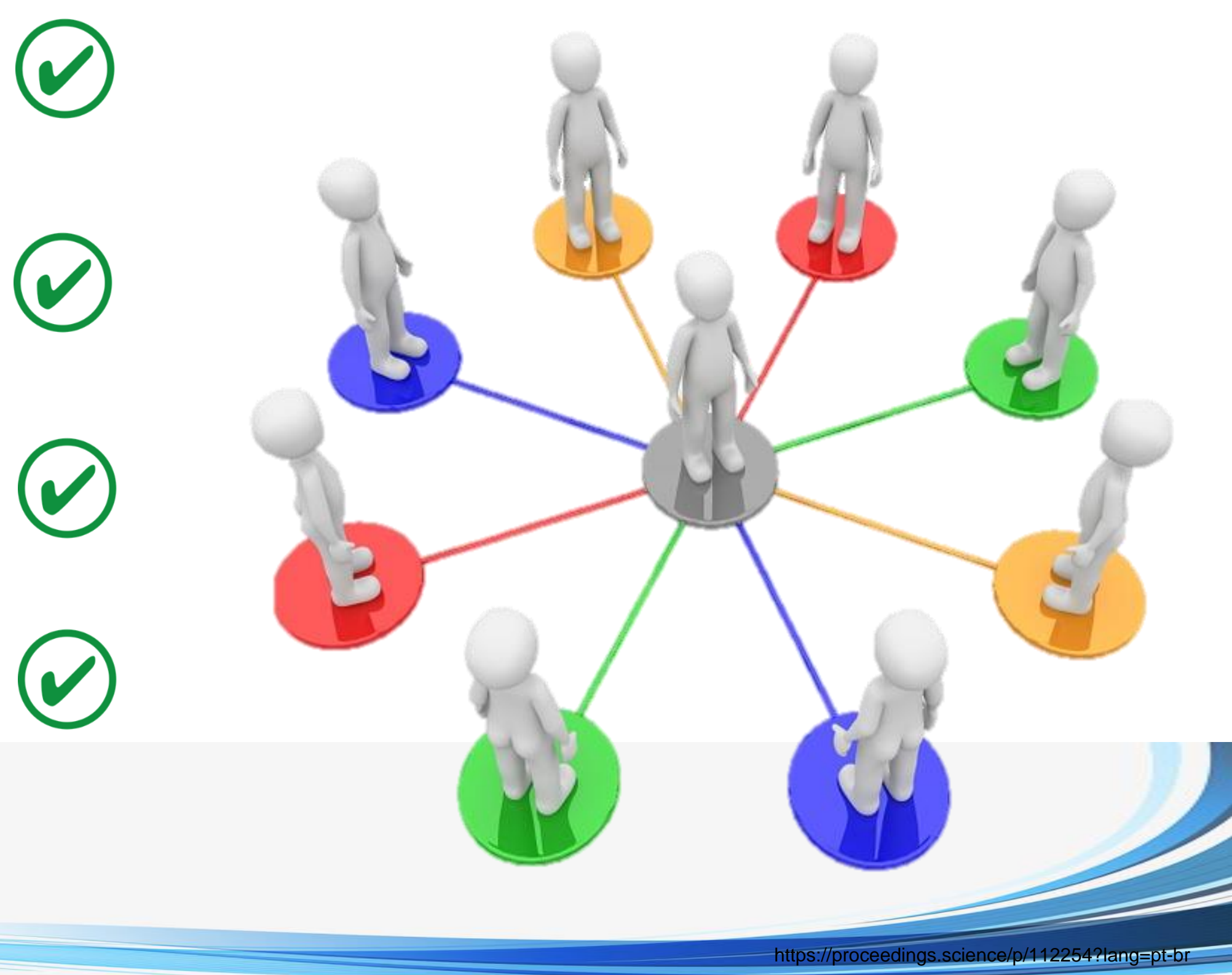


\section{QUEM}

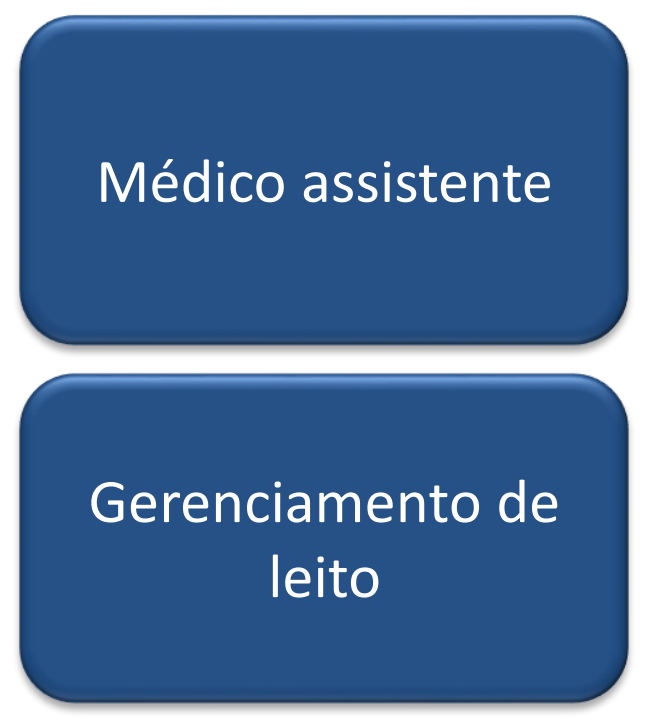

Enfermeiro e Equipe Multidisciplinar

Gerenciamento de leito

\section{QUANDO}

Previsão de alta sistema TASY - PAMD

Formalização via email, de alta para o dia seguinte

Na véspera e no dia da alta realiza as orientações ao paciente e familiar

Diariamente realiza planejamento da gestão dos leitos com as altas programadas

\section{COMO}

Registro e confirmação em campo especifico

Emite relatórios detalhados de previsões de alta no PAMD

Entrega formulários com orientações , documentações e processo de alta

Gestão de leitos para o dia seguinte, disponíveis após as $10 \mathrm{H}$ 

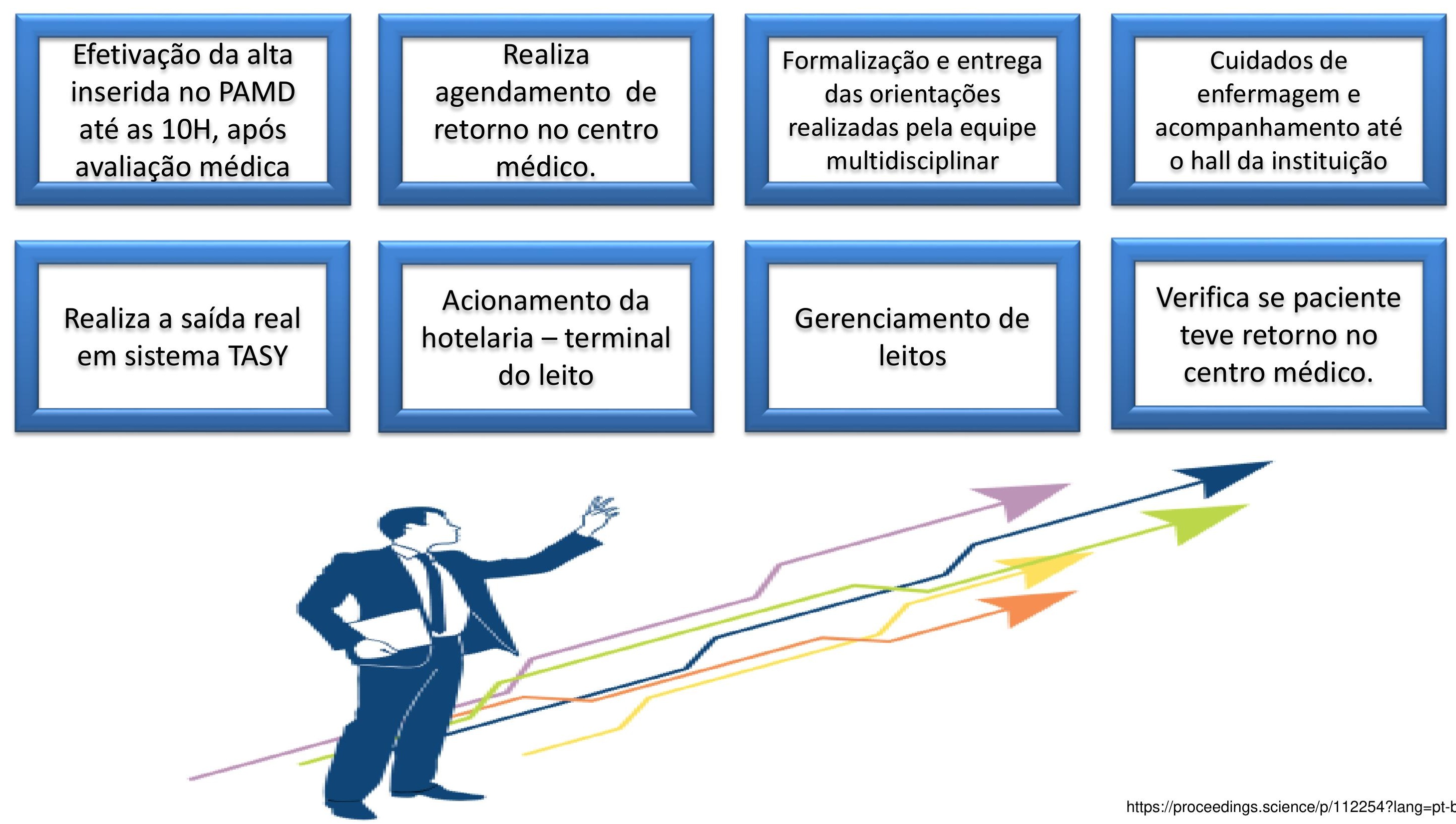
De $\quad 40 \%$

Para $71 \%$

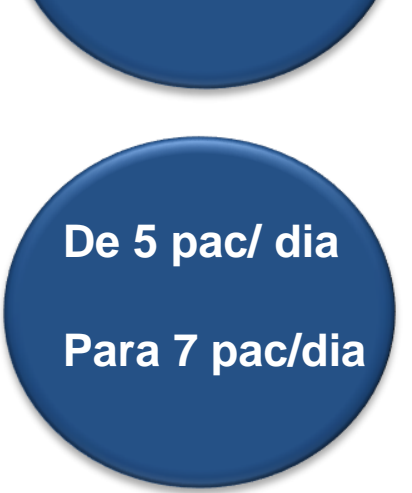

Antes $58 \%$

Depois $75 \%$

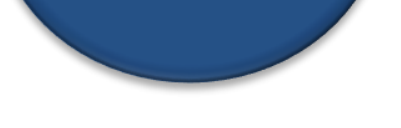

Crescimento de $125 \%$
Aumento do número de altas médicas e desocupação do leito até as $10 \mathrm{H}$.

Aumento do giro de leito hospitalar, contribuindo com resultado financeiro da instituição.

Na pesquisa de satisfação (Hcaphs), a efetividade das orientações de alta hospitalar, influenciando na qualidade percebida

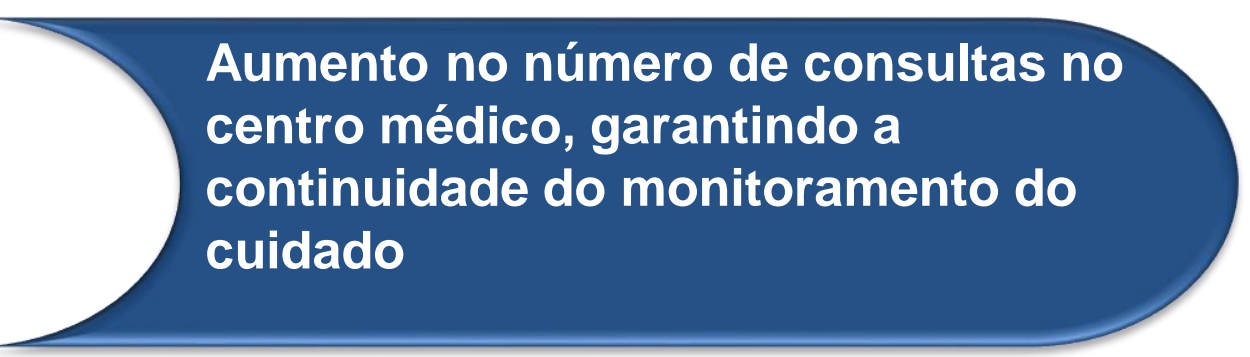


Após a implantação do PAMD, foi identificado melhorias na qualidade técnica, financeira e percebida e ainda estabelecer ações para melhoria de alguns pontos encontrados:

- Sensibilização das equipes médicas, para aumentar a adesão ao PAMD, além a priorização das altas até as $10 \mathrm{H}$, aumentando ainda mais o giro de leito;

- Aumentar conformidade dos registros multidisciplinares das orientações de alta, garantindo a qualidade das orientações proporcionando aumento na adesão ao tratamento pós alta, evitando reinternações não programadas.

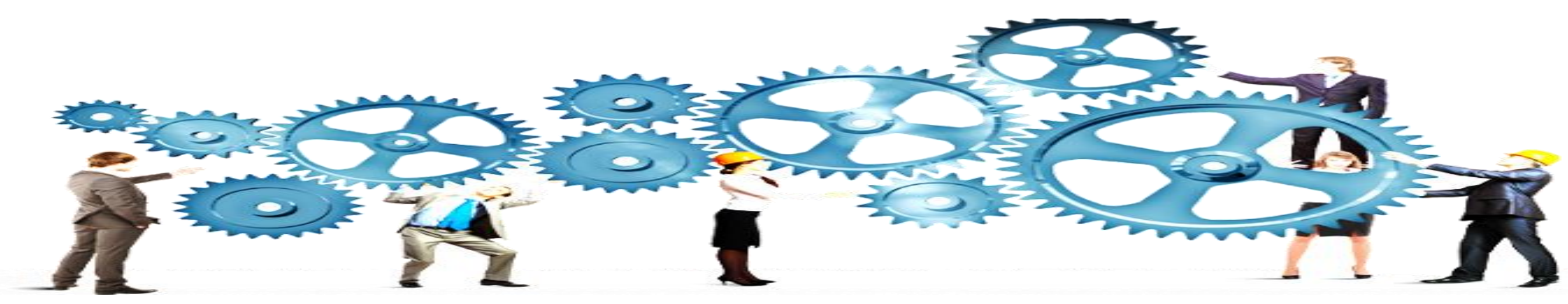


Referências: IGNACIO, Denise Sarreta. Alta hospitalar responsável: em busca da continuidade do cuidado para pacientes em cuidados paliativos no domicílio, uma revisão integrativa. 2017. Dissertação (Mestrado em Tecnologia e Inovação em Enfermagem) - Escola de Enfermagem de Ribeirão Preto, University of São Paulo, Ribeirão Preto, 2017.doi:10.11606/D.22.2017.tde-18072017-092819. Acesso em: 2018-11-14.

Organização Mundial da Saúde.Glossary of Terms for Community Health Care and Services for Older Persons.2004. Disponível em: http://whqlibdoc.who.int/ wkc/2004/WHO WKC Tech.Ser. 04.2pdf. Acesso em:2018-11-05.

CHESANI, F.H; FONTANA,G. Limites e possibilidades no planejamento da alta. Conexão Ci, Formiga/MG, v.12,.2,p.9298,2017. Disponivel em: https://periodicos. uniformg.edu.br:21011/ojs/index.php/conexaociencia/article/view/563/653 .Acesso em: 2018-10-25.
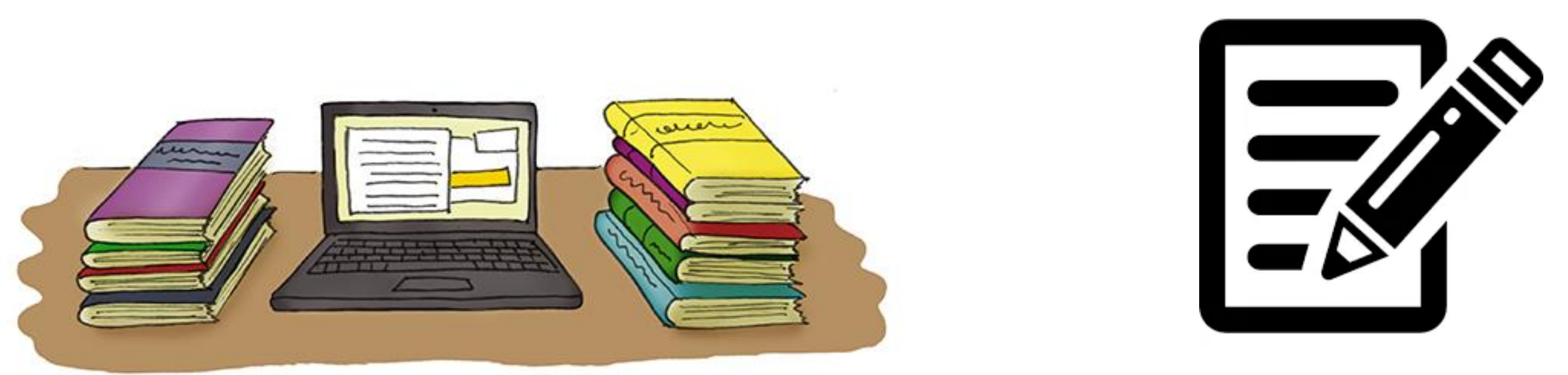


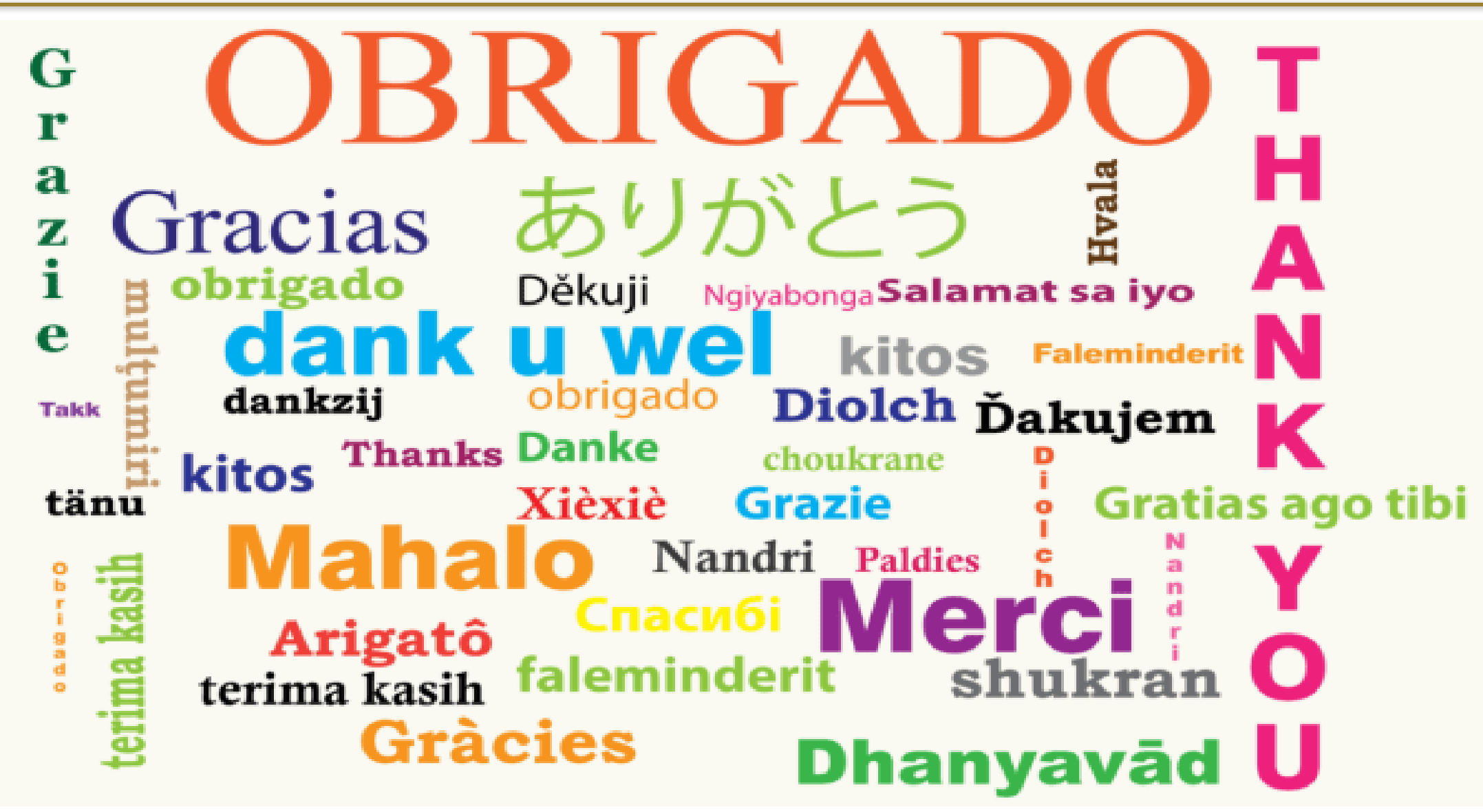

Bruna Luiza Brito Amorim Beloto - Enfermeira Líder Unidade de Internação enfbrunaluiza@hospitalvillalobos.com.br

Roberta Braga Pucci Vale - Supervisora de enfermagem Unidade de Internação enfroberta@hospitalvillalobos.com.br 